\title{
Mechanical Fault Detection on Electrical Machine: Thermal Analysis of Small Brushed DC Motor with Faulty Bearing
}

\author{
Abbas A. Wahab ${ }^{1}, N$. Fatimah Abdullah ${ }^{2}$, M. A. H. Rasid ${ }^{3, *}$ \\ ${ }^{1,2,3}$ Faculty of Mechanical Engineering, Universiti Malaysia Pahang, 26600, Malaysia.
}

\begin{abstract}
Direct current motors (DC motor) are used in the small electric devices commonly. DC motor are cheap and easy to install, thus their popularity. Despite the popularity, faults occur which make diagnosis and detection of faults very important. It avoids financial loss and unexpected shutdown operation causes by these faults. This paper presents an analysis of temperature profile of the much famous small Brushed DC motor with a faulty bearing. The temperature data of healthy DC motor and DC motor with faulty bearing were measured by thermocouple and recorded using data logger in real time until steady state temperature, under different load. The analysis on the steady state temperature allow to conclude that bearing fault can clearly be recognised through characteristics temperature difference with a healthy motor.
\end{abstract}

\section{Introduction}

DC motor is the most common motor used in simple on-board application. Various application with low power (under 250W) in a very large range of area use DC motor. Characterized by simple construction and control, it is largely used even by hobbyist, in electrical learning starter kit on electro-mechanical energy conversion demonstrator and for modular add-on electrical systems [1]. Typical applications of brushed DC motors are in the low voltage ranging from 12-24 V, as found in cost-effective constructions for remote control toys, drone, e-bike, scooter and also automotive drives. These drives are so prevalent that as many as 80 single drives are installed in each of today's luxury cars.

Many researches about Fault Detection and Diagnosis (FDD) of electric motor presented various type of method with different of common fault. The common fault of electric motor can divide by two categories. First category is mechanical fault such as bearing fault, eccentricity fault, rotor shaft bending, commutator fault, brush fault and ventilation system problem [2]. Generally, thermal signal can be used to detect mechanical fault on electric motor. The other category is electrical fault it including stator winding fault, rotor broken bar, wire insulated damage and external sensor devices [3]. Indeed, the most recurrent faults which can be found in the stator part such as short circuits between turns or between phases commonly due to an abnormal elevation of temperature. This can bring insulation degradation, or even in the worst cases short circuit and irreversible damage [4-6]. The same

\footnotetext{
*Corresponding author: mahizami@ump.edu.my
} 
application of thermal assessment for electrical fault as in mechanical fault can be sometime difficult due to inherent nature of Joule losses in conductors. Therefore, plenty other method also exists.

Various type of FDD methods of electric motors can be found in the latest review [7]. Different FDD method for bearing fault were proposed [7-9]. The usual bearing fault are related to the increase of friction due to different reason such as ball damage due to overloading, misalignment and grease leak, usual fatigue inducing cracks or corrosion.

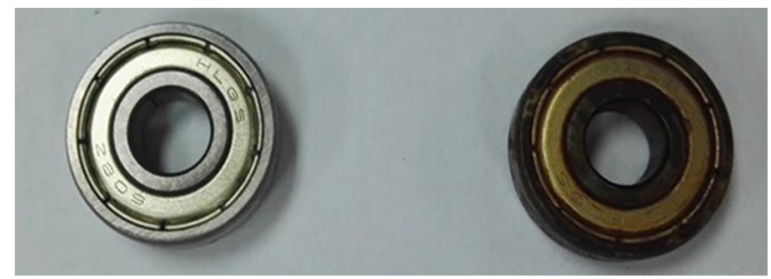

Fig. 1. Particular study case in this paper: Normal bearing (left) and damage bearing (right) due to corrosion.

In this paper, the objective of the study is to study the feasibility of a bearing fault diagnosis via thermal assessment. The particular fault is bearing fault due to corrosion as shown in Figure 1 above. Thermal analysis on faulty motor will be done compared to a healthy reference motor under different load.

\section{Proposed techniques based on recognition of temperature profile}

Temperature is an observable parameter that manifesting the presence of energy in form of heat. The heat in an electric motor comes from Copper Losses originated from the current passing through the conductors. It can be quantified using Equation 1.

$$
P_{\text {copper }}=R \cdot I^{2}
$$

The losses are proportional to the resistance of the conductor $\mathrm{R}$, which is the winding of the motor in the case of electrical machine. It is also proportional to the current square. In principle, the speed of a motor is proportional to the voltage, while the torque is proportional to the current as presented in Equation 2 and Equation 3.

$$
\begin{aligned}
& V=I \cdot R+E ; E=k_{E} \cdot \omega \\
& T=k_{T} \cdot I
\end{aligned}
$$

Therefore, as the load increase, the current increase and generating in consequence higher losses. In this paper, we will maintain the speed as a constant parameter by maintaining the voltage feed to the motor at $5 \mathrm{~V}$. The changing parameter will be the current, and it will be modified by changing the load. The DC motor used in this study has the parameters as listed in the Table 1 below:

Table 1. Specifications of the Brushed DC motor studied.

\begin{tabular}{ll} 
Specification & Detail \\
\hline Model & MY1016 \\
Voltage & 240 VDC \\
\hline
\end{tabular}




\begin{tabular}{ll}
\hline Rated speed & $2650 \mathrm{RPM}$ \\
Rated current & $13.7 \mathrm{~A}$ \\
Output & $250 \mathrm{~W}$ \\
\hline
\end{tabular}

The motor was instrumented by thermocouple on its bearing, brush, permanent magnet and casing.

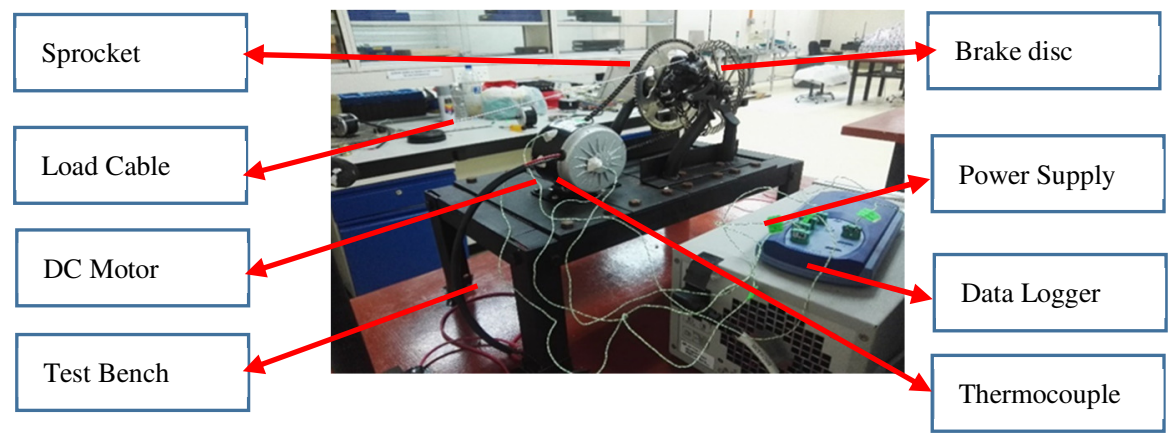

Fig. 2. Experiment setup of Dynamometer test bench.

\section{Methodology}

Fig. 3. The methodology flow chart of temperature profile experiment procedure.

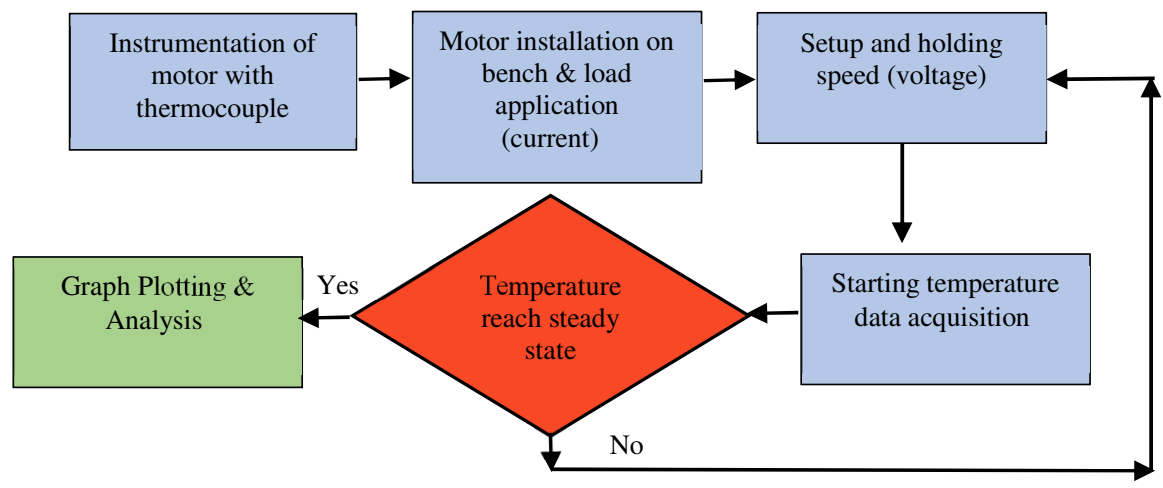

The first step starts with instrumenting the motor with thermocouple on the component to be monitored. The most important part is the bearing. Other parts are also instrumented in order to be compared with. They are casing, permanent magnet, and brush. Once completed, the motor is installed on the test bench as shown in Figure 2, and the thermocouples are attached to the data logger that record and display the temperature on a monitor in real time. The load is then applied to by attaching a mass that pull on a brake system that apply a counter torque to the motor shaft. Then, the motor is switched on and accelerated to the reference speed which is set at $5 \mathrm{~V}$. Two sets of motor (healthy and faulty bearing) were tested under the condition of speed and load parameter as listed in Table 2 below. The healthy and faulty bearing motor are compared under the same speed at different loading.

Table 2. Speed and load parameter of experiment.

\begin{tabular}{ccc} 
Speed $\propto$ Voltage $($ Volt $)$ & Loading & Load $\propto$ Current (Ampere) \\
\hline $5 \mathrm{~V}$ & No-load & $0.5 \mathrm{~A}$ \\
$5 \mathrm{~V}$ & With load & $2.5 \mathrm{~A}$ \\
\hline
\end{tabular}


Once the speed and load set, only then the data acquisition of the temperature rise start to be recorded until the steady state reached. Once the steady state reached, the data recorded are analysed and using graph plotted using the data. The motor is finally unplugged from the power supply and leave to cool down back to the ambient temperature.

\section{Result \& Discussion}

The temperature data recorded for both healthy and faulty bearing motor are then plotted and shown in Figure 4 and Figure 5.

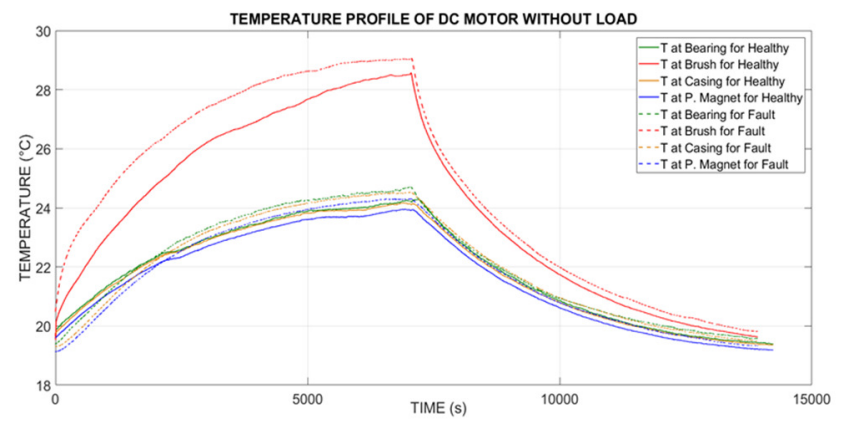

Fig. 4. Temperature profile of healthy and faulty bearing motor at no-load.

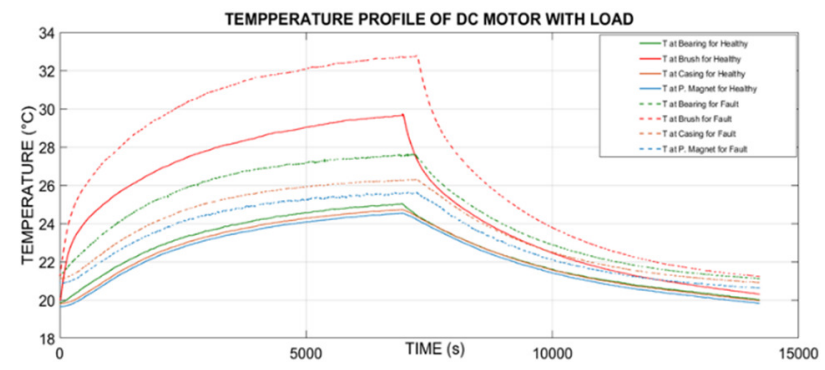

Fig. 5. Temperature profile of healthy and faulty bearing motor at load.

First remark that can be made is that it takes around 7000 seconds for all components to reach steady state temperature. It also takes the same amount of time to cool down and reach back the ambient temperature. The steady state temperature, regardless the loading and fault, are in descending order started with the brush, the bearing, the casing and the permanent magnet. The brush is expected to have the highest temperature as it is an electrical component that conduct current from the power supply to the rotating commutator that deliver the current to the stator of the motor. Therefore, both influence of mechanical friction and copper losses lead to very high temperature. For a more detail steady state temperature analysis, Table 4 presents the steady state temperature of healthy motor at different load and Figure 5 presents the steady state temperature of motor with faulty bearing at different load. On the right column of both tables, the temperature increase in percentage of the comparison between noload and loaded case are presented. Accordingly, a bar chart presenting it is drawn in Figure 6. 
Table 3. Steady state temperature of healthy motor at different load.

\begin{tabular}{cccc} 
DC motor part & $\begin{array}{c}\text { Temperature for } 0.5 \mathrm{~A} \\
\text { DC motor }\left({ }^{\circ} \mathrm{C}\right)\end{array}$ & $\begin{array}{c}\text { Temperature for } 1.5 \mathrm{~A} \\
\text { DC motor }\left({ }^{\circ} \mathrm{C}\right)\end{array}$ & $\begin{array}{c}\text { Temperature increase } \\
\left({ }^{\circ} \mathrm{C}\right) / \%\end{array}$ \\
\hline Bearing & 24.21 & 25.03 & $0.82 / 3.39$ \\
Brush & 28.55 & 29.66 & $1.11 / 3.89$ \\
Casing & 24.11 & 24.73 & $0.62 / 2.57$ \\
P. Magnet & 23.93 & 24.54 & $0.61 / 2.55$ \\
\hline
\end{tabular}

Table 4. Steady state temperature of motor with faulty bearing at different load.

\begin{tabular}{cccc} 
DC motor part & $\begin{array}{c}\text { Temperature for 0.5A } \\
\text { DC } \text { motor }\left({ }^{\circ} \mathrm{C}\right)\end{array}$ & $\begin{array}{c}\text { Temperature for } 1.5 \mathrm{~A} \\
\text { DC motor }\left({ }^{\circ} \mathrm{C}\right)\end{array}$ & $\begin{array}{c}\text { Temperature increase } \\
\left({ }^{\circ} \mathrm{C}\right) / \%\end{array}$ \\
\hline Bearing & 24.71 & 27.61 & $2.90 / 11.74$ \\
Brush & 29.04 & 32.73 & $3.69 / 12.71$ \\
Casing & 24.54 & 26.29 & $1.75 / 7.13$ \\
P. Magnet & 24.31 & 25.60 & $1.29 / 5.31$ \\
\hline
\end{tabular}

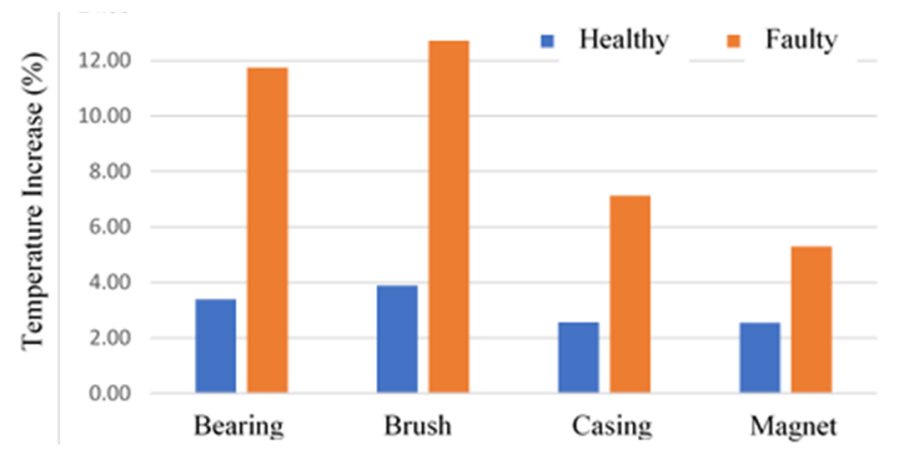

Fig. 6. Temperature increase in percentage (\%) of the comparison between no-load and loaded case.

In general, from Figure 6, from observation that the temperature difference/increase from the case no load with the case loaded is obviously higher for the motor with faulty bearing. Putting aside the brush due to its nature of friction and conductor, the faulty bearing seems to heat more compared to the casing and magnet. The detail of temperature comparison between healthy and faulty motor at both no-load and loaded (Table 5), that the temperature difference of healthy and faulty motor is very small in the case without load throughout the components. None is abnormally higher compared to others. Therefore, at no load, faulty bearing cannot be detected. It is mostly due to

Table 5. Temperature different ( $\Delta$ Temperature) of DC motor between healthy motor and faulty bearing under no load and under load.

\begin{tabular}{cccc}
\multirow{2}{*}{ Part of DC motor } & \multicolumn{2}{c}{$\Delta$ Temperature $\left({ }^{\circ} \mathrm{C}\right)$ (fault-healthy) } & \multirow{2}{*}{ Increase (\%) } \\
\cline { 2 - 3 } & Without load & With load & 262 \\
\hline Bearing part & 0.72 & 2.61 & 941 \\
Brush part & 0.29 & 3.02 & 181 \\
Casing part & 0.61 & 1.72 & 136 \\
Permanent Magnet part & 0.46 & 1.09 & \\
\hline
\end{tabular}


The difference becomes more obvious as the load increase. Again, a remark on the brush temperature increase can be put aside due to its nature of friction and conductors. A fault on the bearing can be remarked as the temperature difference of the bearing distances from the one of casing and permanent magnet. By quantifying the difference in percentage, the bearing counts $262 \%$ of increase compared to $180 \%$ and $136 \%$ of the casing and permanent magnet respectively. Therefore, confidently to concluded that there is a fault on the bearing depends on the temperature profile of DC motor.

\section{Conclusion}

The first conclusion that can be made is that faulty bearing due to corrosion increase overall motor component temperature. Experiments at no load and loaded case demonstrate that the bearing fault could not be detected if the motor is operated at no load. The temperature level on the bearing are only clearly higher to other components when the motor is loaded. Therefore, a bearing fault diagnosis can be done using thermal analysis on a loaded motor. A larger test on a more extensive and higher range of load would certainly put forward the bearing fault.

In a perspective, the proposed diagnostic technique can be extended to higher power electric motor. In the future, we will analyse more high powers electric motors and other faults with various operational parameters. Lastly, a standard temperature table related to load can be developed to help a faster diagnostic.

\section{References}

1. M. N. Modreanu, M. I. Andrei, C. Boboc, M. Morega, 2015 9th Int Symp Adv Top Electr Eng ATEE 2015188 (2015).

2. P. Redón, M. . Picazo-Ródenas, R. J. Romero-Troncoso, J. Antonino-Daviu, 2017 IEEE 11th Int Symp Diagnostics Electr Mach Power Electron Drives (2017).

3. H. Abdallah, K. Benatman, IET Electr Power Appl 11, 272 (2017).

4. M. A. H. Rasid, V. Lanfranchi, K. E. K. Benkara and L. A. O. Vargas, 2013 15th European Conference on Power Electronics and Applications (EPE), Lille,1-10 (2013).

5. M. A. H. Rasid, A. Ospina, K. El Kadri Benkara and V. Lanfranchi, 2014 International Conference on Electrical Machines (ICEM), Berlin, 2199-2204 (2014).

6. M. A. H. Rasid, A. Ospina, K. E. K. Benkara and V. Lanfranchi, 2016 IEEE 25th International Symposium on Industrial Electronics (ISIE), Santa Clara, CA, 134-140 (2016).

7. P. A. Delgado-Arredondo, D. Morinigo-Sotelo, R. A. Osornio-Rios, J. G. AvinaCervantes, H. Rostro-Gonzalez, R. de J. Romero-Troncoso, Mech Syst Signal Process 83, 568 (2017).

8. P. Kripakaran, B. R. Reddy, in 2017 Int Conf Innov Res Electr Sci IICIRES 2017 (2017).

9. C. Sobie, C. Freitas, M. Nicolai, Mech Syst Signal Process 99, 403 (2018). 